inactivated measles virus vaccines. JAMA 202:1075

5. Fulginiti VA, Eller JJ, Eirber OF, Joyner JW, Minamitani M, Meiklejohn G 1969 Respiratory virus immunization. I. A field trial of two inactivated respiratory virus vaccines; an aqueous trivalent parainfluenza virus vaccine and an alum-precipitated respiratory syncytial virus vaccine. Am J Epidemiol $80: 435$

6. Glezen WP, Peredes A, Allison JE, Taber LH, Frank Al 1981 Risk of respiratory syncytial virus infection for infants from low-income families in relationship to age, sex, ethnic group, and maternal antibody level. J Pediatr 98:708

7. Henderson FW, Collier AM, Clyde WA Jr, Denny FW 1979 Respiratorysyncytial-virus infections, reinfections and immunity. A prospective, longitudinal study in young children. N Engl J Med 300:530

8. Kapikian AZ, Mitchell RH, Chanock RM, Shvedoff RA, Stewart CE 1969 An epidemiologic study of altered clinical reactivity to respiratory syncytial (RS) virus infection in children previously vaccinated with an inactivated RS virus vaccine. Am J Epidermiol 80:405

9. Kim HW Arrobio JO, Brandt CD, Jeffries BC, Pybs G, Reid JL, Channock RM, Panott RH: 1973 Epidemiology of respiratory syncytial virus infection in Washington, D. C. I. Importance of the virus in different respiratory tract disease syndromes and temporal distribution of infection. Am J Epidemiol 98:216

10. Kim HW, Canchola JG, Brandt CD, Pyles G, Chanock RM, Jensen J, Parrot
RH 1969 Respiratory syncytial virus disease in infants despite prior administration of antigenic inactivated vaccine. Am J Epidemiol 89:422

11. Lamprecht CL, Krause HE, Mufson MA 1976 Role of maternal antibody in pneumonia and bronchiolitis due to respiratory syncytial virus. J Infect Dis $134: 211$

12. Merz DC, Scheid A, Choppin PW 1980 Importance of antibodies to the fusion glycoprotein of paramyxoviruses in the prevention of spread of infection. J Exp Med 151:275

13. Norrby E, Edners-Ruckle G, Meulen VT 1975 Difference in the appearance of antibodies to structural components of measles virus after immunization with inactivated and live virus. J Infect Dis 132:262

14. Norrby E, Penttinen K 1978 Differences in antibodies to the surface components of mumps virus after immunization with formalin-inactivated and live virus vaccines. $\mathrm{J}$ Infect Dis 138:672

15. Ogilvie MM, Vathenen S, Radford M, Codd J, Key S 1981 Maternal antibody and respiratory syncytial virus infection in infancy. J Med Virol 7:263

16. Parrott RH, Kim HW, Arrobio JO, Hodes DS, Murphy BR, Brandt CD, Camargo E, Chanock RM 1973 Epidemiology of respiratory syncytial virus infection in Washington, D. C. II. Infection and disease with respect to age, immunologic status, race, and sex. Am J Epidemiol 98:289

17. Walsh EE, Hruska J 1983 Monoclonal antibodies to respiratory syncytial virus proteins: identification of the fusion protein. J Virol 47:171

\title{
Lactic Acidosis and Mitochondrial Myopathy Associated with Deficiency of Several Components of Complex III of the Respiratory Chain
}

\author{
NANCY G. KENNAWAY, NEIL R. M. BUIST, VICTOR M. DARLEY-USMAR,' \\ ALEXANDER PAPADIMITRIOU, SALVATORE DIMAURO, RICHARD I. KELLEY, \\ RODERICK A. CAPALDI, NATHAN K. BLANK, AND ANTHONY D'AGOSTINO
}

Departments of Medical Genetics and Pediatrics, Oregon Health Sciences University, Portland, Oregon, 97201 [N.G.K., N.R.M.B.], Institute of Molecular Biology, University of Oregon, Eugene, Oregon, 97403 [V.D-M., R.A.C.J, Department of Neurology and Pathology, Oregon Health Sciences University, Portland, Oregon, 97201 [N.K.B.], Department of Pathology, Good Samaritan Hospital, Portland, Oregon, 97210 [A.D.], Department of Neurology, College of Physicians and Surgeons, Columbia University, New York, New York 10032 [A.P., S.D.], and Division of Biochemical Development and Molecular Diseases, Children's Hospital of Philadelphia, Philadelphia, Pennsylvania 19104 [R.I.K.]

\section{Summary}

We have studied a 17-year-old girl with lactic acidosis (3-18 $\mathrm{mEq} /$ liter) and progressive muscle weakness since 9 years of age. Morphological findings in muscle were of a typical ragged red myopathy with multiple collections of bizarre mitochondria, some containing paracrystalline inclusions.

The carnitine content of serum and muscle was normal, as were the activities of carnitine palmitoyltransferase, carnitine octanoyltransferase, and carnitine acetyltransferase in the patient's muscle. Measurement of the enzymes of oxidative phos-

Received June 13, 1983; accepted December 13, 1983

Correspondence may be addressed to Dr. Nancy G. Kennaway, Oregon Health Sciences University, Pediatric Metabolic Laboratory, Research Bldg., Rm. 508, 3181 SW Sam Jackson Park Rd., Portland, OR 97201.

This work was supported by Grant C-360 from the National Foundation, March of Dimes, to N. R. M. B. and National Institutes of Health Grant HC-22050 to R. A. C.

'Present address: Institute of Basic Medical Sciences, University of Tsukuba, Niihari-gun, Ibaraki 305, Japan. phorylation in both crude muscle homogenates and mitochondrial fractions showed close to normal activities of cytochrome $c$ oxidase, succinate dehydrogenase, and ATPase. In contrast, succinate cytochrome $c$ reductase activity was greatly reduced in the patient, being $0.035 \mu \mathrm{mol} / \mathrm{min} / \mathrm{g}$ tissue in whole muscle (controls $1.16 \pm 0.47 \mu \mathrm{mol} / \mathrm{min} / \mathrm{g}$ tissue) and $8 \mathrm{nmol} / \mathrm{min} / \mathrm{mg}$ protein in the mitochondria (control, $340 \mathrm{nmol} / \mathrm{min} / \mathrm{mg}$ protein). Rotenonesensitive NADH-cytochrome $c$ reductase was also undetectable in the patient's mitochondria. Spectral analysis of cytochromes showed decrease of reducible cytochrome $b$ to $16 \%$ of the control. These results indicate a defect of ubiquinol-cytochrome $c$ reductase or the cytochrome $b c_{1}$ segment (complex III) of the electron transport chain. Antibody-binding studies of the individual components of complex III showed additional deficiencies of core proteins I and II and peptide VI, indicating a more widespread defect of complex III than was evident from spectral analysis and enzyme activity measurements alone.

Urine organic acid analysis after fasting and following a medium chain triglyceride load showed unusually high levels of 
lactate and 3-hydroxybutyrate, lower than expected levels of acetoacetate and dicarboxylic acids, and the presence of several other metabolites suggesting a disturbed citric acid cycle and redox state. Thus, the defect in this patient may be more widespread than is apparent from the clinical presentation.

\section{Abbreviations}

\author{
CNS, central nervous system \\ $\mathrm{CK}$, creatine kinase \\ EMG, electromyogram \\ ECG, electrocardiogram \\ MCT, medium chain triglyceride \\ SDS, sodium dodecyl sulfate \\ DCIP, 2,6-dichloroindophenol
}

A number of distinct hereditary defects of mitochondrial function in muscle have been reported in patients with myopathy. The major function of mitochondria is to provide energy in the form of ATP or creatine phosphate which enables cells to perform a variety of essential functions. The defects which impinge directly on energy metabolism can be divided into four major categories: 1) defects of the carnitine acylcarnitine transport system (muscle carnitine deficiency, systemic carnitine deficiency, carnitine palmitoyltransferase deficiency); 2) defects of mitochondrial matrix enzymes including pyruvate carboxylase, malic enzyme, the pyruvate dehydrogenase complex (pyruvate decarboxylase deficiency, dihydrolipoyl dehydrogenase deficiency, pyruvate dehydrogenase phosphatase deficiency, and possibly dihydrolipoyl transacetylase deficiency), and defects of the tricarboxylic acid cycle ( $\alpha$-ketoglutarate dehydrogenase), or fatty acid degradation; 3 ) defects of the electron transport chain (deficient oxidation of NADH, cytochrome $b$ deficiency, cytochrome $c$ oxidase $\left(a a_{3}\right)$ deficiency, and combined cytochrome deficiencies $\left(a a_{3}+b\right)$; and 4$)$ defects of energy conservation and transduction (hypermetabolic myopathy or Lufts disease, other mitochondrial myopathies with "loose coupling" and mitochondrial ATPase deficiency).

Many of these disorders are classified as "mitochondrial myopathies," a term which implies a myopathic process associated with abnormalities in the number, size, shape, or structure of the mitochondria, evident on microscopic examination. In some of these myopathies, the histological changes may be quite minor; in others, aggregates of mitochondria, occurring in the subsarcolemmal area of the cell, give rise to the so-called ragged red fibers seen with the modified Gomori trichrome stain. Intense staining of these aggregates for succinic dehydrogenase, NADHtetrazolium reductase, or cytochrome oxidase activities confirms their mitochondrial origin. On electron microscopy, the mitochondria are often very bizarre with densely packed cristae or paracrystalline inclusions.

Not all mitochondrial myopathies are primary defects of mitochondrial function (13) and, conversely, some hereditary defects of mitochondria do not produce a typical mitochondrial myopathy. For example, in systemic or muscle carnitine deficiency, the histological findings are generally those of a lipid storage myopathy $(17,24,30)$; in defects of carnitine palmitoyltransferase, pyruvate carboxylase or the pyruvate dehydrogenase complex, the morphological changes in muscle may be slight or even undetectable (30). In several of the mitochondrial deficiencies, tissues other than skeletal muscle may be involved. Examples are the cardiomyopathy associated with muscle carnitine deficiency (21), or the renal Fanconi syndrome described in several patients with cytochrome $c$ oxidase deficiency $(14,43$, 47). Involvement of the CNS also occurs in many of these conditions and may cause overwhelming clinical disease. For example, some patients with disorders of the pyruvate dehydrogenase complex present with hypotonia, progressive encephalopathy, and lactic acidosis, often resulting in death in early infancy
$(11,37,38,45)$. Patients with less severe defects of this system have a much milder phenotype with intermittent ataxia and minimal lactic acidosis (23). Severe lactic acidosis is frequent in patients with pyruvate carboxylase deficiency $(2,22,39,48)$ and mild to severe lactic acidosis is found in defects of the respiratory chain $(14,25,26,31-33,40,43,47,49)$.

The proteins of the inner mitochondrial membrane which comprise the respiratory chain exist as a series of well defined complexes. These are referred to as complex I (NADH-ubiquinone reductase), complex II (succinate-ubiquinone reductase), complex III (ubiquinol-cytochrome $c$ oxidoreductase), and complex IV (cytochrome $c$ oxidase). Each complex contains several distinct polypeptides and two or more redox sites $(3,8,36)$. These complexes are embedded in the inner mitochondrial membrane and mediate the passage of electrons to molecular oxygen. The sequence of reactions which they catalyze is shown in Figure 1. The energy which is generated from electron transport is conserved as a proton and electrochemical gradient at three coupling sites, located in complexes I, III, and IV. The proton gradient is utilized for ion transport or for the synthesis of ATP (complex V). Several patients have been described with defects in the electron transport chain. The sites of these defects have generally been identified by studies of oxygen consumption in the presence of various substrates or by spectral analysis of the cytochromes. More recently, measurements of enzyme activities have helped to localize the sites of these deficiencies $(14,26,33$, $43,47,49)$. However, in no case were the individual polypeptides of complexes I-IV examined, so that the primary lesion in these patients is not known.

Here we report studies on a patient with progressive muscle weakness, mitochondrial myopathy, and lactic acidosis with low levels of reducible cytochrome $b$ and deficient activity of ubiquinol-cytochrome $c$ reductase (complex III) in isolated muscle mitochondria. Examination of the individual polypeptides of complex III with the aid of specific antibodies has shown that, in addition to reducible cytochrome $b$, several other polypeptides were deficient.

\section{CASE REPORT}

Our patient, a 17-year-old girl of Blackfoot Indian, Jewish, and European ancestry, was the product of a normal gestation and birth. She was completely asymptomatic and fully active until age 9 when decreased exercise tolerance was noted. This was attributed to multiple ventricular extrasystoles that developed on minor exertion. Her height and weight, which at 7 years had been in the 50 th percentile, had fallen to the 10 th percentile.

At 10 years, exercise tolerance was worse; muscle cramps and vomiting developed after exercise but muscle weakness was not noted at rest. ECG showed sinus bigeminy for which she received propranolol. Echocardiography was normal and her symptoms were attributed to mild obstrurctive lung disease. Metabolic acidosis was present but was not investigated.

By 15 years of age, the patient developed severe dyspnea after walking only $100-200 \mathrm{~m}$. This was frequently accompanied by leg cramps but no change in urine color. On examination, height and weight were at the 10 th percentile. There was diffuse muscle wasting and marked weakness of all muscle groups. Examination of the heart, eyes, and central nervous system was normal. Laboratory values included normal blood urea nitrogen, creatinine, glutamate oxalacetic transaminase, alkaline phosphatase, thyroid function tests and immunologic tests. The CK was 356 IU ( $n=10-200 \mathrm{IU})$. EMG showed a myopathic picture. Urinalysis showed a trace of protein and some ketones. Systemic acidosis with an anion gap of 17-28 was evident. Prior to an exercise test on a treadmill, the serum lactate was $3.4 \mathrm{mEq} / \mathrm{liter}$; within $3 \mathrm{~min}$ her pulse rate was 160 and she was exhausted. At that stage, the $\mathrm{pH}$ was 7.2 and serum lactate was $13.2 \mathrm{mEq} / \mathrm{liter}$; the $\mathrm{CK}$ did not rise. Histochemical examination of muscle 


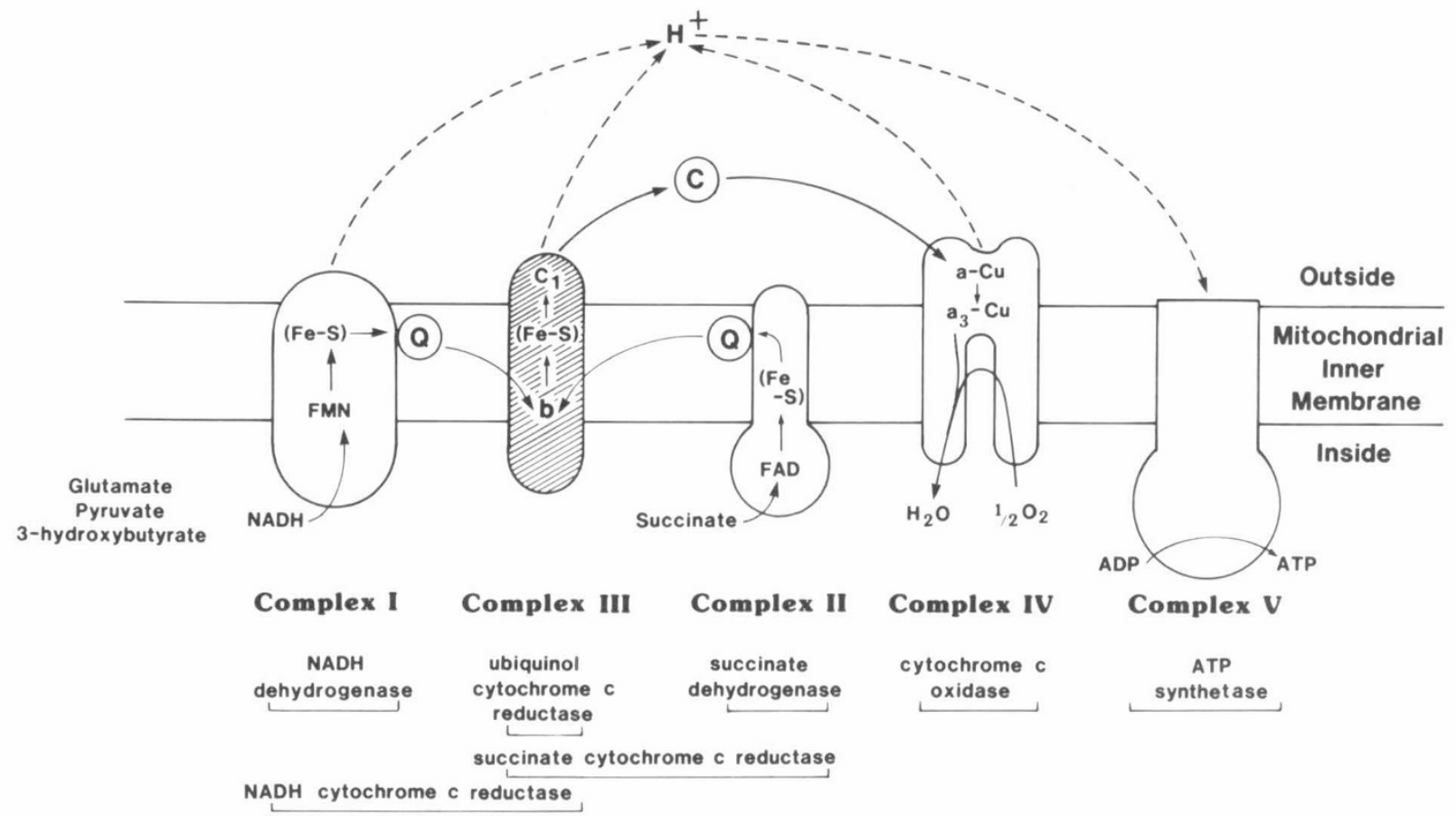

Fig. 1. The electron transport chain. The electron transport complexes I-IV are shown with their prosthetic groups and probable orientation with respect to the mitochondrial inner membrane. The electron pathway from substrate to molecular oxygen is shown by the arrows; the proton gradient generated by electron transport at complexes I, III, and IV (dashed line) is utilized at complex V to generate ATP. The hatched area of complex III indicates the site of the defect in the patient. $F M N$, flavine mononucleotide; $F A D$, flavine adenine dinucleotide; $F e-S$, one or more nonheme iron-sulfur proteins; these are shown in parentheses to indicate that their exact location in the sequence of electron transfer reactions is not known with certainty; $Q$, coenzyme $\mathrm{Q}$ (ubiquinol/ubiquinone); $b, c_{1}, c, a, a_{3}=$ mitochondrial cytochromes.

showed a ragged red fiber myopathy with degenerating and regenerating fibers, and electron microscopy revealed abnormal mitochondria with crystalline structures within them. The glycogen and fat content of the cells was increased.

Between the age of 15 and 17 years, the patient's tolerance for exercise became even more limited so that she missed most of one school year. At 17 years, she had an episode of severe metabolic acidosis resulting in prolonged vomiting and a seizure; the serum lactate was $18.2 \mathrm{mEq} /$ liter. Since then, she has been taking sodium bicarbonate, $300 \mathrm{mEq} /$ day. This has helped to control the acidosis but the serum lactate has remained elevated, ranging from 3-13.2 mEq/liter. Blood pyruvate on two occasions was 1.6 and $3.2 \mathrm{mg} / \mathrm{dl}$ (normal, $0.3-0.9 \mathrm{mg} / \mathrm{dl}$ ). The lactate/ pyruvate ratio was also elevated, 26 and 29 (normal $<20$ ). Serum amino acids were normal, except alanine which was $0.76 \mu \mathrm{mol} /$ $\mathrm{ml}$ (normal, $0.21-0.66 \mu \mathrm{mol} / \mathrm{ml}$ ). Urine amino acid chromatography also showed a slight elevation of alanine. Gas chromatography of organic acids in two random urine samples showed greatly increased lactate and 2-hydroxybutyrate, a small peak of 3-hydroxybutyrate and no other abnormalities.

After the lactic acidosis was discovered, a therapeutic trial with several vitamins was started. These included thiamine $(500 \mathrm{mg} /$ day), pyridoxine $(250 \mathrm{mg} /$ day $)$, biotin $(20 \mathrm{mg} /$ day $)$, nicotinic acid $(50 \mathrm{mg} /$ day $)$, and riboflavin $(50 \mathrm{mg} /$ day $)$. None seemed to ameliorate the symptoms.

Recent neurological examination was normal except for peripheral muscle weakness without atrophy. ECG and auditory evoked responses were normal. Routine visual testing and electroogulography were also normal; however, an electroretinogram was marginally abnormal and dark adaptometry showed elevated cone and rod thresholds with periodic fluctuations possibly related to retinal fatigue.

\section{MATERIALS AND METHODS}

Control and patient muscles were obtained by open biopsy after signed permission and informed consent were given. Tissue for biochemical analysis was frozen immediately and stored at $-70^{\circ} \mathrm{C}$. A portion of tissue for microscopy was placed in $10 \%$ formalin and a further portion was frozen for histochemistry. Tissue for electron microscopy was placed immediately in $1.5 \%$ glutaraldehyde/1.5\% paraformaldehyde in cacodylate buffer.

Frozen sections of muscle were examined with the modified Gomori trichrome stain (18) and tested for succinic dehydrogenase (34), NADH-tetrazolium reductase (19), and acid phosphatase (4) activities according to standard procedures.

Gas chromatography of urine organic acids. Organic acids were extracted from acidified urine into ethyl acetate, converted to trimethylsilyl derivatives, and quantitated by gas chromatography on a $10 \%$ OV-1 column according to standard procedures (27). Peak identities were confirmed by mass spectrometry.

Tissue preparation. Muscle extracts were prepared by homogenization in 9 volumes of $0.15 \mathrm{M} \mathrm{KCl}, 50 \mathrm{mM}$ Tris- $\mathrm{HCl}, \mathrm{pH}$ 7.4 , in all-glass motor-driven homogenizers. Crude muscle enzyme activities were measured in supernatants obtained after centrifugation at $1000 \times g$ for $15 \mathrm{~min}$. Free carnitine was measured in neutralized supernatants of $10 \%$ muscle homogenates precipitated with equal volumes of $10 \%$ perchloric acid after centrifugation at $27,000 \times g$ for $15 \mathrm{~min}$ as described previously (14).

For spectral analysis and measurement of other enzyme activities in crude mitochondrial preparations, approximately $1 \mathrm{~g}$ of tissue was cut into small pieces and placed in $10 \mathrm{ml}$ buffer containing $0.20 \mathrm{M}$ sucrose, $0.13 \mathrm{M} \mathrm{NaCl}$, and $1 \mathrm{mM}$ Tris- $\mathrm{HCl}$, $\mathrm{pH} \mathrm{7.4}$. This was stirred on ice for $30 \mathrm{~min}$ with $0.14 \mathrm{mg}$ of collagenase (Sigma type VII). Samples were homogenized with a loose fitting, motor-driven, Potter-Elvehjem homogenizer and then with a tight fitting homogenizer. The solution was centrifuged at $500 \times g$ for $10 \mathrm{~min}$ and the precipitate was discarded. The supernatant was centrifuged at $8000 \times g$ for $15 \mathrm{~min}$ and the crude mitochondrial pellet was suspended in the isolation buffer.

Activity measurements. Free carnitine concentrations were measured by the method of McGarry and Foster (29) except that Hepes buffer was used instead of Tris- $\mathrm{HCl}$. Carnitine palmitoyl- 
transferase and carnitine octanoyltransferase were measured by "isotope exchange" assays (6), and carnitine acetyltransferase by a spectrophotometric procedure (28). Other enzyme activities in crude muscle homogenates were measured as described previously (14).

In mitochondrial preparations, NADH-cytochrome $c$ reductase was determined by the method of Sottocasa et al. (41). Two distinct enzyme systems contribute to this activity; the first, which is rotenone-insensitive, is associated with the outer mitochondrial membrane (41) whereas the second, which is rotenonesensitive, is associated with the inner mitochondrial membrane and functions in the electron transport chain (complexes I and III). NADH-cytochrome $c$ reductase, measured in the absence of rotenone, reflects the sum of these activities. Rotenone-sensitive $\mathrm{NADH}$-cytochrome $c$ reductase was obtained by subtracting the value obtained in the presence of rotenone from that obtained in the absence of rotenone.

Cytochrome $c$ oxidase activity was measured spectrophotometrically by following the oxidation of ferrocytochrome $c$ at $550 \mathrm{~nm}$. The assay was performed in a buffer containing $0.5 \%$ Tween $80,50 \mathrm{mM}$ potassium phosphate, $\mathrm{pH}$ 7.0. The use of detergent allows disruption of the outer mitochondrial membrane so that optimal rates can be measured. The final concentration of ferrocytochrome $c$ was $10 \mu \mathrm{M}$ and that of mitochondrial protein $0.013 \mathrm{mg} / \mathrm{ml}$. Rates were calculated from the plot of $\log \left(A_{550}-A_{550}\right.$ at $\left.\infty\right)$ and are expressed as nanomoles cytochrome $c$ oxidized $/ \mathrm{min} / \mathrm{mg}$ protein.

Succinate dehydrogenase activity was measured spectrophotometrically using 2,6-dichloroindophenol as the electron acceptor and succinate as the electron donor. The reaction was monitored at $600 \mathrm{~nm}$. Mitochondria $(1 \mathrm{mg} / \mathrm{ml})$ were activated prior to assay by incubation with $40 \mathrm{mM}$ succinate and then diluted to $0.035 \mathrm{mg} / \mathrm{ml}$ into the cuvette for assay. The assay buffer contained $1.5 \mathrm{mM} \mathrm{KCN}, 16 \mathrm{mM}$ succinate, $0.0015 \%$ 2,6-dichloroindophenol, and $50 \mathrm{mM}$ potassium phosphate, $\mathrm{pH}$ 7.0.

Succinate-cytochrome $c$ reductase activity was measured by following the reduction of ferricytochrome $c$ at $550 \mathrm{~nm}$. Additions were identical to those described for the succinate dehydrogenase activity except 2,6-dichloroindophenol was omitted. The concentration of cytochrome $c$ in the cuvette was $13.6 \mu \mathrm{M}$.

ATPase activity was also monitored spectrophotometrically in the absence and presence of dicyclohexyl carbodiimide (44). All assays were conducted at $37^{\circ} \mathrm{C}$ using a Beckman DU7 spectrophotometer.

Spectral analysis of cytochromes. Difference spectra of the cytochromes (dithionite reduced-oxidized) were recorded at room temperature in mitochondria solubilized in $1 \%$ Triton X-

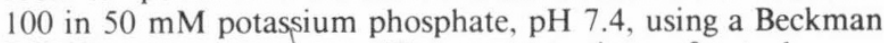
DU 7 spectrophotometer. The concentrations of cytochromes were calculated using the extinction coefficients of Bookelman et al. (7).

Antibody-binding experiments. Subunits of purified beef heart complex III were prepared by gel filtration in Bio-gel P-100 after dissociation by SDS. Purity of the fractions was judged by SDSpolyacrylamide gel electrophoresis. Antibodies were raised in rabbits against the purified components of complex III. One preparation of anti-complex III antibody was the generous gift of Dr. J. Hare, Oregon Health Sciences University, Portland. SDS-polyacrylamide gels were made as described by Fuller et al. (20) and Western blots were performed as described by Towbin et al. (46) with the addition of $0.1 \%$ SDS to the electrophoresis buffer.

\section{RESULTS}

Muscle Histochemistry. Semithin, plastic-embedded, toluidine blue-stained sections showed muscle fibers which did not vary greatly in size or shape. The connective tissue appeared normal. There was no fiber degeneration or inflammatory infiltrates and subsarcolemmal inclusions were absent. Subserial frozen sections of right quadriceps muscle were further examined. With hematoxylin and eosin, many of the muscle fibers contained an increased amount of bluish-red granular sarcoplasm. In the modified Gomori trichrome preparations, numerous ragged red fibers were present (Fig. 2). The red granular material was present beneath the sarcolemma and within the more central portions of the muscle fibers. Scattered subsarcolemmal vacuoles were also noted. With both succinic dehydrogenase and NADH-tetrazolium reductase preparations, there was marked increase in the amount of reaction product within individual fibers. With Oil Red O, many muscle fibers contained increased amounts of lipid. In the acid phosphatase preparations, there was an increased amount of reaction product in many of the affected muscle fibers. This reaction product was not present within vacuoles.

Electron Microscopy. Electron microscopy of muscle revealed several fibers with internally located nuclei. The myofilamentous architecture was intact, and the plasmalemmal-basal laminar complex was continuous. Some fibers contained subsarcolemmally placed collections of bizarre mitochondria (Fig. 3). Many of these mitochondria had unusual shapes and were overly large. Others contained disrupted cristae and round or longitudinally oriented paracrystalline inclusions. Glycogen particles and lipid droplets did not appear to be increased. One terminal nerve twig was seen and was normal. Electron microscopy of peripheral blood leukocytes and cultured skin fibroblasts revealed no abnormalities.

Response to fasting and to oral medium chain triglycerides. In order to evaluate our patient's ability to generate ketone bodies, she fasted for 8-9 $\mathrm{h}$ and then was given an oral load of $50 \mathrm{ml}$ MCT oil (mostly $\mathrm{C}_{6}, \mathrm{C}_{8}$, and $\mathrm{C}_{10}$ fatty acids) and sequential 2-hr urine samples were collected. The major urinary organic acids in the fasting (preload) and 4-6-hr postload samples are shown in Table 1. Several organic acids, notably lactate and 3-hydroxybutyrate, were greatly increased in the 8-9-hr fasting sample. Following the MCT load, lactate, 3-hydroxybutyrate, acetoacetate, and sebacate increased substantially, but the increase in adipate and suberate was low for the degree of ketosis (35). Citrate also appeared lower than normal. Several other unusual metabolites were present in both samples, particularly fumarate, malate, 2-ketoglutarate, and 7-hydroxyoctanoate.

Biochemical Studies. The content of free carnitine in muscle from the patient was $2.08 \mu \mathrm{mol} / \mathrm{g}$ wet weight (controls, $2.34 \pm$ $0.87 \mu \mathrm{mol} / \mathrm{g}$ wet weight; $n=56$ ). In serum, free carnitine was $27.3 \mu \mathrm{mol} / \mathrm{ml}$ (controls, $51.1 \pm 11.1 \mu \mathrm{mol} / \mathrm{ml} ; n=59$ ). These values, along with the normal activity of carnitine palmitoyltransferase, carnitine octanoyltransferase, and carnitine acetyltransferase (Table 2 ) ruled out a defect of the carnitine acylcarnitine system in this patient.

A number of other enzyme activities were also measured in crude homogenates of muscle and these are shown in Table 2. The activity of succinate-cytochrome $c$ reductase was diminished to about $3 \%$ of the mean control value whereas all other enzyme activities were normal or increased. Mixing experiments with control and patient tissue showed no reduction over expected values for succinate-cytochrome $c$ reductase, indicating that the reduced activity in the patient's muscle was not due to the presence of an inhibitor.

The activities of several enzymes, measured in a mitochondrial preparation isolated from frozen muscle, are shown in Table 3. Succinate-cytochrome $c$ reductase activity was again strikingly diminished; succinate dehydrogenase, however, was only slightly below the control value. Rotenone-sensitive NADH-cytochrome $c$ reductase was also undetectable in the patient compared to the controls. The normal activity of total NADH-cytochrome $c$ reductase in crude muscle homogenate is apparently of no value in indicating a deficiency of ubiquinol-cytochrome $c$ reductase, presumably because the loss of this activity on the inner mitochondrial membrane is masked by the normal enzyme activity associated with the outer membrane. These results indicate a 


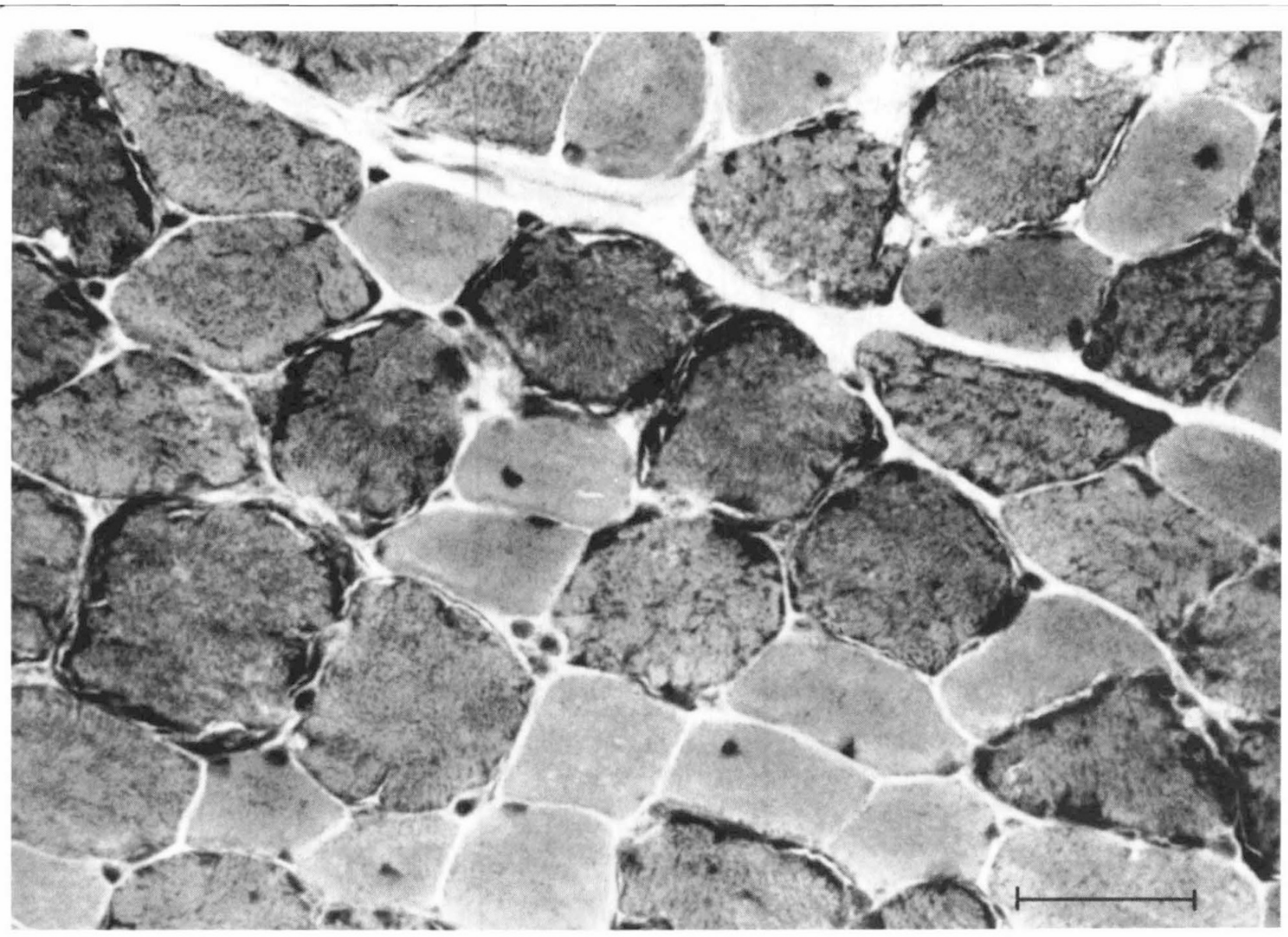

Fig. 2. Muscle biopsy stained with the modified Gomori trichrome stain. Bar $=40 \mu \mathrm{m}$.



Fig. 3. Electron micrograph of section of muscle showing aggregates of bizarre mitochondria. $\times 20,000$. 
Table 1. Urine organic acids after fasting (preload) and 4-6 $h$ following medium chain triglyceride load

\begin{tabular}{lrr}
\hline \multicolumn{1}{c}{ Acid } & $\begin{array}{r}\text { Preload } \\
(\mathrm{mg} / \mathrm{g} \text { creatinine })\end{array}$ & $\begin{array}{r}\text { Postload } \\
\text { Lactic }\end{array}$ \\
2-Hydroxybutyric & 2,844 & 17,040 \\
3-Hydroxybutyric & 171 & 912 \\
Acetoacetic & 2,539 & 13,208 \\
Succinic & 114 & 1,800 \\
Fumaric & 114 & 228 \\
Glutaric & 58 & 128 \\
Adipic & 21 & 20 \\
Malic & 40 & 123 \\
7-Hydroxyoctanoic & 150 & 120 \\
2-Ketoglutaric & 122 & 180 \\
4-Hydroxyphenylacetic & 192 & 261 \\
Suberic & 110 & 19 \\
cis-Aconitic & 101 & 122 \\
Hippuric & 285 & 138 \\
Citric & 2,095 & 347 \\
Sebacic & 53 & $<10$ \\
\hline
\end{tabular}

Table 2. Enzyme activities in crude muscle homogenates

\begin{tabular}{lcc}
\hline & Patient & Controls* \\
\hline Cytochrome $c$ oxidase & 3.91 & $2.38 \pm 0.44(22)$ \\
NADH-cytochrome $c$ reductase & 3.20 & $2.97 \pm 1.00(18)$ \\
$\quad(-$ rotenone) & & \\
$\quad \begin{array}{l}\text { Succinate-cytochrome } c \text { reduc- } \\
\quad \text { tase }\end{array}$ & $0.032,0.037$ & $1.16 \pm 0.47(17)$ \\
Carnitine acetyltransferase & 1.54 & $1.57 \pm 0.48(21)$ \\
Carnitine octanoyltransferase & 0.343 & $0.257 \pm 0.054(19)$ \\
Carnitine palmitoyltransferase & 0.172 & $0.092 \pm 0.010(10)$ \\
\hline
\end{tabular}

* Control values are mean $\pm \mathrm{SD}$ with number of samples in parentheses. Activities are expressed as $\mu \mathrm{mol} / \mathrm{min} / \mathrm{g}$ tissue.

Table 3. Enzyme activities in muscle mitochondria*

\begin{tabular}{lcc}
\hline & Patient & Controls \\
\hline ATPase & 2000 & 1200 \\
Cytochrome $c$ oxidase & 1222 & 945 \\
NADH-cytochrome $c$ reductase & 0 & $136 \pm 43 \dagger$ \\
$\quad$ (rotenone-sensitive) & 57 & \\
Succinate dehydrogenase & 8 & 340 \\
Succinate-cytochrome $c$ reduc- & & \\
$\quad$ tase & & \\
\hline
\end{tabular}

${ }^{*}$ Activities are expressed as $\mathrm{nmol} / \mathrm{min} / \mathrm{mg}$ mitochrondrial protein.

$\dagger$ Mean \pm SD of five samples.

defect in ubiquinol-cytochrome $c$ reductase or complex III of the electron transport chain (Fig. 1).

Figure 4 shows the reduced-oxidized difference spectra of the cytochromes obtained from mitochondrial preparations of patient and control muscle. The characteristic absorbance maxima of cytochrome $b$ at $428 \mathrm{~nm}$ in the Soret region and at $562 \mathrm{~nm}$ in the $\alpha$ band region were greatly diminished in the patient's sample. The relative amounts of cytochromes, calculated from these spectra, are reported in Table 4 and confirm the marked deficiency of cytochrome $b$ in the patient. In the presence of antimycin A, which inhibits electron transport at the level of cytochrome $b$, the concentration of cytochrome $b$ in control muscle rose by $51 \%$ whereas in the patient's muscle it fell by $33 \%$. These data confirm the deficiency of cytochrome $b$ in the patient and are compatible with the enzyme activity measurements reported above, indicating a defect at the level of complex III (Fig. 1).

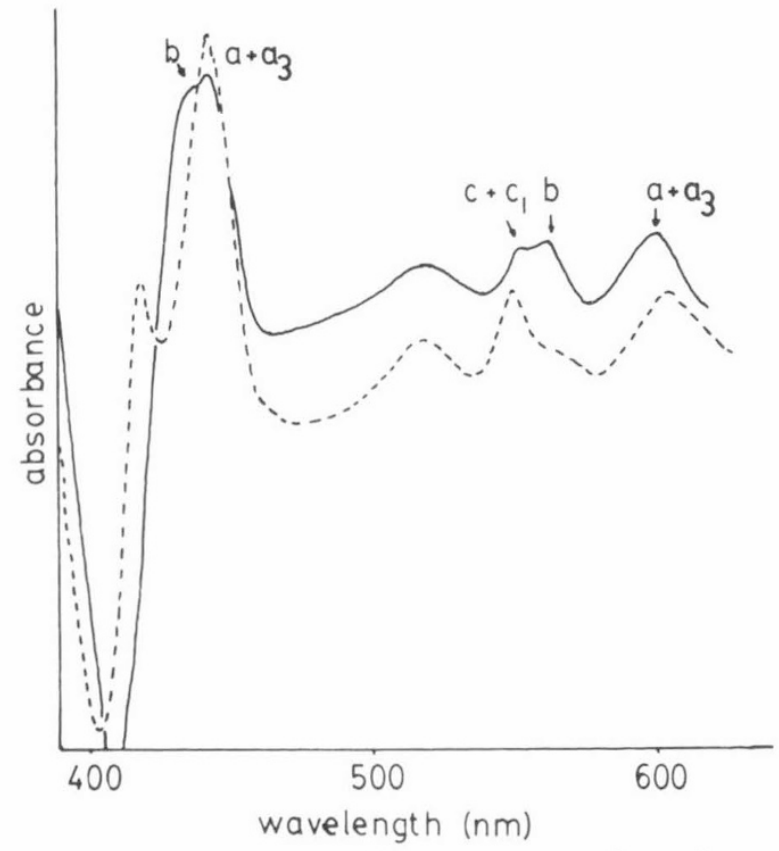

Fig. 4. Room temperature difference spectra of cytochromes (reduced-oxidized) from muscle mitochondrial preparations. The absorption maxima of cytochromes $a+a_{3}, b$, and $c+c_{1}$ are indicated with arrows.

Table 4. Cytochrome content of muscle mitochondria*

\begin{tabular}{lll}
\hline & Patient & Control \\
\hline Cytochrome $a+a_{3}$ & 0.6 & 1.0 \\
Cytochrome $b$ & 0.1 & 0.63 \\
Cytochrome $c+c_{1}$ & 0.66 & 0.66 \\
\hline
\end{tabular}

* Cytochromes are expressed as $\mathrm{nmol} / \mathrm{mg}$. The concentration of cytochrome $a$ is expressed as $a+a_{3}$; however, since the cytochrome oxidase molecule contains both heme groups in one complex, the concentration of cytochrome oxidase is then one-half that of cytochrome $a+a_{3}$ reported above. Our values are expressed as cytochrome $a+a_{3}$ to enable comparison with other workers. It should be emphasized that the extinction coefficient reported by Bookelman et al. (7) is for heme $a$ and the values should be divided by 2 to give the concentration of cytochrome oxidase.

Complex III consists of 10 constituent polypeptides (8). In order to determine which of these proteins were affected in the patient, antibody-binding experiments were performed. The mitochondrial proteins were first separated by SDS-polyacrylamide gel electrophoresis, and then transferred to nitrocellulose paper. The transferred proteins were incubated with antibodies raised in rabbits against native beef heart complex III dissolved in $0.1 \%$ Triton X-100. The subunit-specific antibodies were visualized by binding fluorescein isothiocyanate-labeled goat anti-rabbit antibody. Figure 5, lane 1, shows antibody binding to purified beef heart complex III. It is clear that only a few of the polypeptide subunits react with antibody under these conditions. This is not unexpected since the antibody was raised against native protein in which some subunits may be masked by either detergent or by the other subunits. Under such conditions, the antigenic subunits are most likely to be exposed to the aqueous phase. This is in fact the case for core proteins 1 and 2, cytochrome $c_{1}$, and subunit VI which are all exposed $(5,16)$. In the patient (Fig. 5 , lane 2) compared to control human muscle (lane 3), virtual absence of core proteins 1 and 2, close to normal levels of cytochrome $c_{1}$, and absence of peptide VI are demonstrated. These deficiencies, in addition to the low levels of reducible cytochrome $b$, indicate a more generalized defect of complex III than was evident by the spectral analysis and enzyme activity measurements alone. 


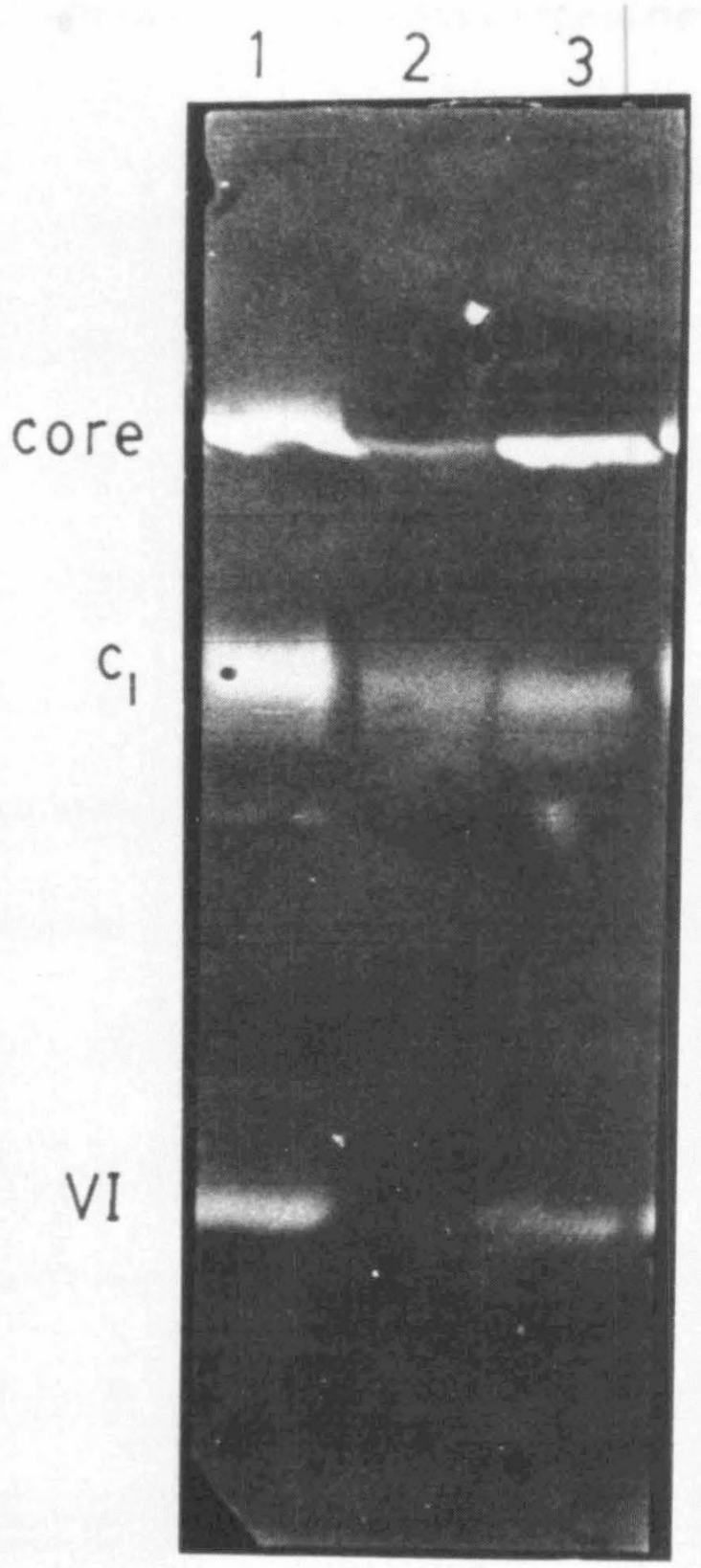

Fig. 5. Binding of anticomplex III antibodies to subunits of ubiquinol cytochrome $c$ reductase (complex III). The subunits of the beef heart enzyme were identified by comparison with a duplicate gel stained for protein. Core proteins 1 and 2 migrate as one band under these conditions. (mol wt $\sim 45,000$ ); $c_{1}$, cytochrome $c_{1}$ (mol wt $\sim 30,000$ ); VI, subunit VI ( $\mathrm{mol}$ wt $\sim 16,000$ ). l, $2 \mu \mathrm{g}$ purified beef heart complex III; 2 , $80 \mu \mathrm{g}$ of mitochondrial protein from patient muscle; $3,80 \mu \mathrm{g}$ of mitochondrial protein from control muscle.

\section{DISCUSSION}

Our patient has suffered from slowly progressive exercise intolerance and muscle weakness since 9 years of age. Although she was noted to have a metabolic acidosis at the age of 10 , lactic acidosis was not documented until several years later. This oversight should be emphasized since many physicians are not attuned to investigate minor degrees of metabolic acidosis. The absence of hypoglycemia and central nervous system signs reduced the likelihood of a defect of pyruvate carboxylase or the pyruvate dehydrogenase complex. However, the association of lactic acidosis with muscle weakness and the appearance of a typical ragged red fiber myopathy has been reported in several patients believed to have a disorder of the respiratory chain including NADH-coenzyme Q reductase deficiency $(25,26,32$, $33,40)$, cytochrome $b$ deficiency $(31,33,42)$, and cytochrome $c$ oxidase deficiency $(14,15,43,47,49)$. With the exception of cytochrome oxidase, most of these deficiencies have been deduced from spectral or oxygen consumption studies alone. However, with complexes at the beginning of the electron transfer pathway, such measurements are prone to artifact.

Measurement of enzyme activities in both crude muscle homogenates and in mitochondrial preparations revealed deficient activity of succinate-cytochrome $c$ reductase in our patient. Normal activity of succinate dehydrogenase with DCIP as an electron acceptor and lack of detectable rotenone-sensitive NADH-cytochrome $c$ reductase activity in the patient indicate the defect is at the level of ubiquinol-cytochrome $c$ reductase. The spectral analysis of cytochromes in mitochondrial preparations of muscle revealed a striking deficiency of reducible cytochrome $b$ in the patient. Since cytochrome $b$ is a constituent of complex III, this is consistent with the results discussed above. Two types of cytochrome $b$ with different redox potential are present in complex III (36). In the spectra shown here, the two forms are not distinguishable. Since only one mitochondrial structural gene appears to code for apocytochrome $b$, the spectroscopic differences are probably induced after synthesis and integration into complex III.

Deficiency of cytochrome $b$ has previously been reported in four patients. Two of these, a father and son, presented with progressive ataxia, muscle weakness, insidious dementia, and other findings which suggested a spinocerebellar degenerative disorder (42). Respiration of mitochondria was $25-30 \%$ of normal with glutamate plus malate or with succinate and was insensitive to the action of antimycin A, suggesting a defect of respiration at the level of cytochrome $b$. Cytochrome $b$ levels in the two patients were 24 and $44 \%$ of normal, respectively. Cytochrome $a$ was also reduced to approximately $50 \%$ of normal. Morgan-Hughes and co-workers have described two additional unrelated patients with apparent deficiency of cytochrome $b(31$, 33). Clinically, the first patient was similar to our patient, with slowly progressive muscle weakness and fatiguability, whereas the second patient had CNS dysfunction with involuntary jerking movements, ataxia, disorientation, confusion, paranoia, mild deafness, and visual impairment in addition to muscle weakness. Both patients had ragged red fiber myopathy; elevated lactate concentrations were reported in urine of the first case and in blood of the second. In both patients, respiratory rates were low with pyruvate plus malate or with succinate, and the content of cytochrome $b$ was diminished. In none of these four patients with cytochrome $b$ deficiency were the activities of succinatecytochrome $c$ reductase or NADH-cytochrome $c$ reductase measured. However, a defect of ubiquinol-cytochrome $c$ reductase could be inferred from the oxygen consumption and spectral studies.

The data reported for our patient have demonstrated, for the first time, a specific deficiency of ubiquinol-cytochrome $c$ reductase or complex III activity of human mitochondrial inner membrane. Complex III is a multicomponent protein composed of 10 distinct polypeptides (8). These include core proteins 1 and 2 , a nonheme Fe-S center, cytochrome $b$, cytochrome $c_{1}$, and five additional polypeptides. For the antibody-binding studies, antibodies were raised against native purified complex III from beef heart; these cross-react with human complex III as shown in Figure 5 (lane 3). This is not unexpected since the mitochondrial electron transfer proteins are highly conserved $(1,12)$. Only three bands were resolved in these preparations, representing cross-reaction with four proteins (core proteins 1 and 2 comigrate under these electrophoretic conditions). The other proteins of complex III may not elicit antibody in this preparation because of shielding by other protein subunits or detergent. Deficiencies in core proteins 1 and 2 as well as subunit VI are evident in the patient's sample. Cytochrome $c_{1}$ appeared to be present in normal amount and this is consistent with the normal 
concentration of cytochrome $c+c_{1}$ measured spectrally. We have no information on the presence or absence of the other subunits of complex III. Thus, the lesion extends to at least four polypeptides of complex III and is not restricted to reducible cytochrome $b$.

It is known that cytochrome $b$ is coded for by mitochondrial DNA whereas the other nine peptides of complex III are coded for by nuclear DNA (1). The nature of the primary defect which gives rise to deficiency of several polypeptides, coded for by both nuclear and mitochondrial DNA is not known. Further antibodybinding experiments have been undertaken to define more precisely the extent of the abnormality of mitochondrial inner membrane components in this patient and these are reported elsewhere (10).

There are several puzzling features of the clinical presentation of this patient and others with similar defects of electron transport. In particular, it is unclear why muscles, and possibly the retina, seem to be the only tissues affected. There is no clinical evidence for liver or kidney involvement; liver function tests are normal and there is no Fanconi syndrome. However, the urinary organic acid excretion patterns following fasting and the response to an MCT load may be relevant to this question. If the defect in complex III occurred in the liver, then one might expect to see poor $\beta$-oxidation of fatty acids which usually results in $\omega$ oxidation with urinary excretion of dicarboxylic acids. By contrast, the degree of ketoacidosis in the fasting sample was excessive for only 8-9 h of fasting in an adult, whereas the dicarboxylic acids, adipic and suberic, were relatively much reduced for the degree of ketosis. In addition, the $\beta$-hydroxybutyrate/acetoacetate ratio was abnormally high, presumably reflecting an increased mitochondrial NADH/NAD ratio (50). This might also explain the low level of citrate, secondary to reduced oxaloacetate production from malate via NAD-dependent dehydrogenation. The presence of several citric acid cycle metabolites, particularly fumarate and malate, has been reported in other patients with primary lactic acidosis $(8,40)$. Whether these derive from faulty renal metabolism or are filtered from the blood is not clear. Finally, the presence of 7-hydroxyoctanoic acid in the fasting urine sample is unusual. This product of $\omega$-1 oxidation has been reported in patients with defects of mitochondrial $\beta$-oxidation (9) but its significance in this case is not clear. Following the MCT load, urine lactate and 3-hydroxybutyrate rose dramatically, the $\beta$-hydroxybutyrate/acetoacetate ratio remained abnormally high, and the increase in dicarboxylic acid excretion was lower than in control subjects. The undetectable level of citrate in the postload urine suggests a further depression of oxaloacetate production from malate because of a worsening redox state and/ or reduced generation from other sources such as aspartate or pyruvate. Although these results provide no evidence for a block in fatty acid $\beta$-oxidation, as might have been expected from the deficiencies of complex III, they do suggest a deranged energy metabolism in liver and/or kidney, which can largely be explained by a relative deficiency of NAD.

Another puzzling aspect of our patient's presentation is that there were no symptoms until 9 years of age although she was fully active until that time. The increasing disability over the past few years implies that the disorder is progressive and suggests that there may be differences in the regulation of the respiratory components in different tissues and at different ages. However, with the present data, we cannot distinguish between a regulatory or structural gene defect, or even rule out the possibility of some outside environmental agent in the etiology of this condition. The answer to these questions awaits further understanding of the control of expression of the various components of the respiratory chain in different tissues and the nature of the primary defect in these patients.

Acknowledgements. We are grateful to Dr. Stu Levy, Kaiser Permanente Clinic, Portland, for referring this patient and for help with her clinical care and to Dr. Richard G. Weleber, Oregon
Health Sciences University, Portland, for ophthalmologic studies.

\section{REFERENCES}

1. Anderson S, Bankier AT, Barrell BG, de Bruijn MHL, Coulson AR, Drouin J, Eperon IC, Nierlich DP, Roe BA, Sanger F, Schreier PH, Smith AJH, Staden R. Young IG 1981 Sequence and organization of the human mitochondrial genome. Nature 290:457

2. Atkin BM, Buist NRM, Utter MF, Leiter AB, Banker BQ 1979 Pyruvate carboxylase deficiency and lactic acidosis in a retarded child without Leigh's disease. Pediatr Res 13:109

3. Azzi A 1980 Cytochrome $c$ oxidase. Towards a clarification of its structure, interactions and mechanism. Biochim Biophys Acta 594:231

4. Bancroft JD 1967 An Introduction to Histochemical Technique, p 192. Appleton-Century-Crofts, New York

5. Bell RL, Sweetland J, Ludwig B, Capaldi RA 1979 Labeling of complex III with $\left[{ }^{35} \mathrm{~S}\right]$ diazobenzenesulfonate: orientation of this electron transfer segment in the mitochondrial inner membrane. Proc Natl Acad Sci USA 76:741

6. Bertorini T, Yeh Y-Y, Trevisan C, Stadlan E, Sabesin S, DiMauro S 1980 Carnitine palmityl transferase deficiency: myoglobinuria and respiratory failure. Neurology 30:263

7. Bookelman H, Trijbels JMF, Sengers RCA, Janssen AJM 1978 Measurement of cytochromes in human skeletal muscle mitochondria, isolated from fresh and frozen stored muscle specimens. Biochem Med 19:366

8. Capaldi RA 1982 Arrangement of proteins in the mitochondrial inner membrane. Biochim Biophys Acta 694:291

9. Colle E, Mamer OA, Montgomery JA, Miller JD 1983 Episodic hypoglycemia with $\psi$-hydroxy fatty acid excretion. Pediatr Res 17:171

10. Darley-Usmar VM. Kennaway NG, Buist NRM, Capaldi RA 1983 Deficiency in ubiquinol cytochrome $c$ reductase in a patient with mitochondrial myopathy and lactic acidosis. Proc Natl Acad Sci USA 80:5103

11. DeVivo DC. Haymond MW, Obert KA, Nelson JS, Pagliara AS 1979 Defective activation of the pyruvate dehydrogenase complex in subacute necrotizing encephalomyelopathy (Leigh disease). Ann Neurol 6:483

12. Dickerson RE, Timkovich R, Almassy RJ 1976 The cytochrome fold and the evolution of bacterial energy metabolism. J Mol Biol 100:473

13. DiMauro S 1979 Metabolic myopathies. In: Vinken PJ, Bruyn GW (eds) Handbook of Clinical Neurology, vol 41, p 175. North-Holland Publishing Co, Amsterdam

14. DiMauro S, Mendell JR. Sahenk Z. Bachman D. Scarpa A, Scofield RM, Reiner C 1980 Fatal infantile mitochondrial myopathy and renal dysfunction due to cytochrome-c-oxidase deficiency. Neurology 30:795

15. DiMauro S, Nicholson JF, Hays AP, Eastwood AB, Koenigsberger R, DeVivo DC 1981 Benign infantile mitochondrial myopathy due to reversible cytochrome $c$ oxidase deficiency. Ann Neurol 10:90

16. D'Souza MP, Wilson DF 1982 Labeling of succinate-cytochrome $c$ reductase with ${ }^{125} \mathrm{I}$. J Biol Chem 257:11760

17. Engel AG 1980 Possible causes and effects of carnitine deficiency in man. In: Frenkel RA, McGarry JD (eds) Carnitine Biosynthesis, Metabolism and Function, p 271. Academic Press, New York

18. Engel WK. Cunningham GC 1963 Rapid examination of muscle tissue. An improved trichrome method for fresh-frozen biopsy specimens. Neurology 13:919

19. Farber E, Sternberg WH Dunlap CE 1956 Histochemical localization of specific oxidative enzymes. III. Evaluation studies of tetrazolium staining methods for diphosphopyridine nucleotide diaphorase, triphosphopyridine nucleotide diaphorase and the succindehydrogenase system. J Histochem Cytochem 4:284

20. Fuller SD, Darley-Usmar VM, Capaldi RA 1981 Covalent complex between yeast cytochrome $c$ and beef heart cytochrome $c$ oxidase which is active in electron transfer. Biochemistry 20:7046

21. Hart ZH, Chang C-H. DiMauro S. Farooki Q, Ayyar R 1978 Muscle carnitine deficiency and fatal cardiomyopathy. Neurology 28:147

22. Haworth JC. Robinson BH, Perry TL 1981 Lactic acidosis due to pyruvate carboxylase deficiency. J Inher Metab Dis 4:57

23. Kark RAP, Rodriguez-Budelli M 1979 Pyruvate dehydrogenase deficiency in spinocerebellar degenerations. Neurology 29:126

24. Karpati G, Carpenter S, Engel AG, Watters G, Allen J, Rothman S, Klassen G, Mamer OA 1975 The syndrome of systemic carnitine deficiency. Neurology $25: 16$

25. Kerr DS, Parland WK, Wyatt DT, Miller-Paulson S, Dahms BB, Hoppel CL 1980 NADH dehydrogenase deficiency with lactic acidosis, fatty infiltration of viscera and abnormal mitochondria. Pediatr Res 14:576

26. Land JM, Morgan-Hughes JA. Clark JB 1981 Mitochondrial myopathy. Biochemical studies revealing a deficiency of NADH-cytochrome $b$ reductase activity. J Neurol Sci 50:1

27. Lawson AM, Chalmers RA, Watts RWE 1976 Urinary organic acids in man. I. Normal patterns. Clin Chem 22:1283

28. Marquis NR, Fritz IB 1965 The distribution of carnitine, acetylcarnitine and carnitine acetyltransferase in rat tissues. J Biol Chem 240:2193

29. McGarry JD, Foster DW 1976 An improved and simplified radioisotopic assay for the determination of free and esterified carnitine. J Lipid Res 17:277

30. Mitchell ME 1978 Carnitine metabolism in human subjects. III. Metabolism in disease. Am J Clin Nutr 31:645

31. Morgan-Hughes JA, Darveniza P, Kahn SN, Landon DN, Sherratt RM, Land JM, Clark JB 1977 A mitochondrial myopathy characterized by a deficiency 
in reducible cytochrome $b$. Brain 100:617

32. Morgan-Hughes JA, Darveniza P, Landon DN, Land JM, Clark JB 1979 A mitochondrial myopathy with a deficiency of respiratory chain NADH-CoQ reductase activity. J Neurol Sci 43:27

33. Morgan-Hughes JA, Hayes DJ, Clark JB, Landon DN, Swash M, Stark RJ, Rudge P 1982 Mitochondrial encephalomyopathies. Biochemical studies in two cases revealing defects in the respiratory chain. Brain 105:553

34. Nachlas MM, Tsou K-C, De Souza E, Cheng C-S, Seligman AM 1957 Cytochemical demonstration of succinic dehydrogenase by the use of a new $p$ nitrophenyl substituted ditetrazole. J Histochem Cytochem 5:420

35. Pettersen JE, Jellum E, Eldjarn L 1972 The occurrence of adipic and suberic acid in urine from ketotic patients. Clin Chim Acta 38:17

36. Rieske JS 1976 Composition, structure and function of complex III of the respiratory chain. Biochim Biophys Acta 456:195

37. Robinson BH, Sherwood WG 1975 Pyruvate dehydrogenase phosphatase deficiency: a cause of congenital chronic lactic acidosis in infancy. Pediatr Res 9:935

38. Robinson BH, Taylor J, Sherwood WG 1977 Deficiency of dihydrolipoyl dehydrogenase (a component of the pyruvate and $\alpha$-ketoglutarate dehydrogenase complexes): a cause of congenital chronic lactic acidosis in infancy. Pediatr Res. 11:1198

39. Saudubray JM, Marsac C, Charpentier C, Cathelineau L, Beeson Leaud M, Leroux JP 1976 Neonatal congenital lactic acidosis with pyruvate carboxylase deficiency in two siblings. Acta Paediatr Scand 65:717

40. Senior B, Jungas RJ 1974 A disorder resulting from an enzymatic defect of the respiratory chain. Pediatr Res 8:438a

41. Sottocasa GL, Kuylenstierna B, Ernster L, Bergstrand A 1967 An electrontransport system associated with the outer membrane of liver mitochondria. A biochemical and morphological study. J Cell Biol 32:415

42. Spiro AJ, Moore CL, Prineas JW, Strasberg PM, Rapin I 1970 A cytochrome- related inherited disorder of the nervous system and muscle. Arch Neurol $23: 103$

43. Stansbie D, Dormer RL, Hughes IA, Minchom PE, Hendry GAF, Jones OTG, Cross AR, Sherratt HSA, Turnbull DM, Johnson MA 1982 Mitochondrial myopathy with skeletal muscle cytochrome oxidase deficiency. J Inher Metab Dis 5:27 (Suppl 1)

44. Stiggall DL, Galante YM, Hatefi Y 1979 Preparation and properties of complex V. Methods Enzymol 55:308

45. Strömme JH, Borud O, Moe PJ 1976 Fatal lactic acidosis in a newborn attributable to a congenital defect of pyruvate dehydrogenase. Pediatr Res 10:60

46. Towbin H, Staehelin T, Gordon J 1979 Electrophoretic transfer of proteins from polyacrylamide gels to nitrocellulose sheets: procedure and some applications. Proc Natl Acad Sci 76:4350

47. Van Biervliet JPGM, Bruinvis L, Ketting D, De Bree PK, van der Heiden C, Wadman SK, Willems JL, Bookelman H, Van Haelst U, Monnens LAH 1977 Hereditary mitochondrial myopathy with lactic acidemia, a DeToniFanconi-Debré syndrome, and a defective respiratory chain in voluntary striated muscles. Pediatr Res 11:1088

48. Van Biervliet JPGM, Bruinvis L, van der Heiden C, Ketting D, Wadman SK. Willems JL, Monnens LAH 1977 Report of a patient with severe, chronic lactic acidaemia and pyruvate carboxylase deficiency. Dev Med Child Neurol 19:392

49. Willems JL, Monnens LAH, Trijbels JMF, Veerkamp JH, Meyer AEFH, van Dam K, van Haelst U 1977 Leigh's encephalomyelopathy in a patient with cytochrome $c$ oxidase deficiency in muscle tissue. Pediatrics 60:850

50. Williamson DH, Lund P, Krebs HA 1967 The redox state of free nicotinamideadenine dinucleotide in the cytoplasm and mitochondria of rat liver. Biochem J 103:514

\title{
A Monoclonal Antibody Recognizes Structural Variation in Cystic Fibrosis $\alpha_{2}$-Macroglobulin
}

\author{
KENDRA B. EAGER AND ROGER H. KENNETT \\ Department of Human Genetics, University of Pennsylvania School of Medicine, \\ Philadelphia, Pennsylvania 19104
}

\section{Summary}

$\alpha_{2}$-Macroglobulin $\left(\alpha_{2} \mathbf{M}\right)$ is a major plasma protease inhibitor that has been studied because of its suggested role in the pathology of cystic fibrosis (CF). A panel of monoclonal antibodies specific for human $\alpha_{2} \mathrm{M}$ were produced and screened for their ability to bind to a number of human $\alpha_{2} M$ samples. We have used these antibodies to characterize individual antigenic sites in this protein. $\alpha_{2} \mathrm{M}$ was purified from plasma by polyethylene glycol precipitation followed by zinc chelate chromatography. A total of $23 \alpha_{2} \mathrm{M}$ samples in the native configuration, as well as the nucleophile-treated configuration, were screened by the panel of 18 monoclonal antibodies in an enzyme-linked immunosorbent assay procedure. Five of the samples tested were from individuals with cystic fibrosis. $\alpha_{2} \mathrm{M}$ from family members of two of these patients was subsequently tested for reactivity with the monoclonal antibodies. One antibody, SAM94, exhibited a significant difference in binding to $\alpha_{2} \mathrm{M}$ obtained from $\mathrm{CF}$ patients as compared with control individuals. This difference was particu-

Received November 4, 1983; accepted February 7, 1984.

Reprint requests may be addressed to Kendra B. Eager, The Wistar Institute, 36th and Spruce Streets, Philadelphia, PA 19104

4263 larly apparent in the binding of SAM94 to the nucleophile-treated CF $\alpha_{2}$ M; SAM94 showed significantly reduced binding to four of five unrelated CF individuals $(p<0.005)$ and three of four cystic fibrosis obligate heterozygotes $(p<0.005)$.

\section{Abbreviations}

$\alpha_{2} \mathrm{M}, \alpha_{2}$-macroglobulin

CF, cystic fibrosis

ELISA, enzyme-linked immunosorbent assay

PEG, polyethylene glycol

PBS, phosphate-buffered saline

PMSF, phenylmethylsulfonyl fluoride

SBTI, soybean trypsin inhibitor

TEMED, $N, N, N^{\prime}, N^{\prime}$-tetramethylethylenediamine

$\alpha_{2} \mathrm{M}$ is a plasma glycoprotein that functions in the inhibition and elimination of proteases from the plasma (16). The molecule, composed of four subunit chains of 185,000 molecular weight (11), binds irreversibly to the active form of proteases, changing the conformation of $\alpha_{2} \mathrm{M}$ and thereby trapping the enzyme (2). A similar conformational change can be mimicked by treatment 